\title{
Aydın bölgesindeki üst gastrointestinal sistem malignitelerinin özellikleri
}

\author{
Features of upper gastrointestinal tract malignancies in Aydin region
}

Adil COŞKUN ${ }^{1}$, Serkan BORAZAN ${ }^{1}$, Vahit YÜKSELEN ${ }^{1}$, Ibrahim METEOĞLU², İmran KURT ÖMÜRLÜ³ Mehmet Hadi YAŞA ${ }^{1}$

Adnan Menderes Üniversitesi Tip Fakültesi, ${ }^{1}$ Gastroenteroloji Bilim Dall, ${ }^{2}$ Patoloji Anabilim Dall, ${ }^{3}$ Biyoistatistik Anabilim Dal, Aydın

Giriş ve Amaç: Üst gastrointestinal sistem maligniteleri tüm dünyada önemli mortalite ve morbidite nedenlerindendir. Tanıda özofagogastroduodenoskopi altın standart işlemdir. Çalışmadaki amacımız endoskopi ünitemizde özofagogastroduodenoskopi işlemi ile tespit ettiğimiz ve biyopsi ile de tanısı kesinleşen üst gastrointestinal sistem malignitelerinin yaş, cinsiyet, lokalizasyon ile histopatolojik tipleri ve işlem öncesi hasta semptomlan gibi bazı özelliklerini belirlemekti. Gereç ve Yöntem: Endoskopi ünitemizde özofagogastroduodenoskopi yapılan 7.688 hastadan malignite saptanan 209 (\%2,71) vaka çalışmaya alındı. Bulgular: Özofagogastroduodenoskopi işleminde malignite saptanan hastaların 145'i erkek $(\% 69,4), 64$ 'ü kadın

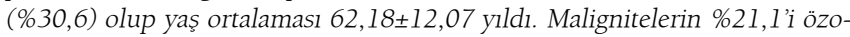
fagusta, \%75, l'i midede ve \%3,8'i duodenumda saptand. Yapilan histopatolojik incelemede, özofagus kanserlerinin \%84,1'i squamöz hücreli karsinom, \%15,9'u adenokarsinom; mide kanserlerinin \%87,9'u adenokarsinom, \%3,8'i malign epitelyal tümör, \%5,8'i lenfoma, \%2,5'i nöroendokrin tümör; duodenum kanserlerinin \%87,5'i adenokarsinom, \%12,5'i malign epitelyal tümör olarak tespit edildi. Sonuç: Üst gastrointestinal sistem maligniteleri en sık midede, 2. siklıkta özofagusta saptanmaktadır. Nadirde olsa duodenumda tümör görülebilmektedir.

Anahtar kelimeler: Özofagogastroduodenoskopi, malignite
Background and Aims: Upper gastrointestinal tract malignancies are among the major causes of morbidity and mortality worldwide. Esophagogastroduodenoscopy is the gold standard for the diagnosis of upper gastrointestinal tract cancers. The aim of our study was to determine features of upper gastrointestinal tract malignancies including age, gender, localization, histological types and symptoms prior to the procedure in the cases that were identified by in our endoscopy unit and finally diagnosed by biopsy. Materials and Methods: A total of 209 (2.71\%) of 7.688 patients who underwent esophagogastroduodenoscopy in our endoscopy unit and who were diagnosed with malignancy were included in the study. Results: Of the patients diagnosed with malignancy by esophagogastroduodenoscopy, 145 were men $(69,4 \%)$ and 64 were women $(30,6 \%)$. Mean age was 62.18 12.07 years. In the sample, $21.1 \%$ of malignant tumors were detected in the esophagus, $75.1 \%$ in the stomach, and $3.8 \%$ in the duodenum. Histopathological examination showed that $84.1 \%$ of esophageal tumors were squamous cell carcinoma, and $15.9 \%$ were adenocarcinoma; $87.9 \%$ of gastric tumors were adenocarcinoma, 3.8\% were malignant epithelial tumors, $5.8 \%$ were $1 y m$ phoma, and $2.5 \%$ were neuroendocrine tumors; $87.5 \%$ of duodenal tumors were adenocarcinoma, and $12.5 \%$ were malignant epithelial tumors. Conclisions: Upper gastrointestinal tract malignancies are most common in the stomach, and the second most common organ is esophagus. Although rare, tumors can be seen in the duodenum.

Key words: Esophagogastroduodenoscopy, malignancy

incelendi. Özofagus, mide ve duodenumda tümör saptanan ve histopatolojik olarak malignitesi doğrulanan 209 (\%2,71) vaka çalışmaya dahil edildi. Tespit edilen tümörlerin lokalizasyonu, histopatolojik tipi ile işlem öncesi hasta semptomları ve demografik verileri değerlendirmeye alındı. Tanımlayıcı istatistikler ortalama \pm standart sapma, frekans ya da yüzde olarak gösterildi.

\section{BULGULAR}

Endoskopi ünitemizde ÖGD yapılan 7.688 hastanın 209 $(\% 2,71)$ tanesinde malignite tespit edildi. Malignite saptanan hastaların 145'i erkek $(\% 69,4), 64$ 'ü kadın $(\% 30,6)$ olup yaş ortalaması $62,18 \pm 12,07$ ylld. Malignitelerin \%21,1'i özofagusta, \%75,1'i midede ve \%3,8'i duodenumda saptandi. Özofagusta tespit edilen 44 malignitenin 27'si erkeklerde, 17 tanesi kadınlarda, midede tespit edilen 157 malignitenin 46's1 kadinlarda 111'i erkeklerde ve duodenumda tespit edilen 8 
Tablo 1. Üst gastrointestinal sistem malignitelerinin anatomik yerleșim yeri ve cinslere göre dağılımı

\begin{tabular}{|lccc}
\hline Yerleşim Yeri & Erkek n (\%) & Kadın n (\%) & Toplam n (\%) \\
\hline Özofagus & & & \\
\hline \multicolumn{1}{|c|}{ Proksimal $1 / 3$} & $6(60,0)$ & $4(40,0)$ & $10(100)$ \\
\hline Orta $1 / 3$ & $6(42,9)$ & $8(57,1)$ & $14(100)$ \\
\hline Distal 1/3 & $15(64,3)$ & $5(35,7)$ & $20(100)$ \\
\hline Toplam & $27(61,4)$ & $17(38,6)$ & $44(100)$ \\
\hline Mide & & & \\
\hline \multicolumn{1}{|c|}{ Kardia } & $39(68,4)$ & $18(31,6)$ & $57(100)$ \\
\hline Fundus & $6(85,7)$ & $1(14,3)$ & $7(100)$ \\
\hline Korpus & $48(75)$ & $16(25)$ & $64(100)$ \\
\hline Antrum & $18(62,1)$ & $11(37,9)$ & $29(100)$ \\
\hline Toplam & $111(70,7)$ & $46(29,3)$ & $157(100)$ \\
\hline Duodenum & & & $4(100)$ \\
\hline Bulbus & $3(75)$ & $1(25)$ & $4(100)$ \\
\hline Duo. 2. kısım & $4(100)$ & $0(0)$ & $8(100)$ \\
\hline Toplam & $7(87,5)$ & $1(12,5)$ & \\
\hline
\end{tabular}

tümörün 7'si erkeklerde ve l'i kadınlarda saptandı. Özofagus tümörlerinin \%22,7'si proksimalde, \%31,8'i orta özofagusta ve $\% 45,5$ 'i distaldeydi. Mide tümörlerinin \%36,3’ü kardiada, $\% 4,5$ 'i fundusta, \%40,7'si korpusta ve \%18,5'i antrumdayd. Duodenum tümörlerinin \%50'si bulbusta ve \%50'si 2. kısımdayd. Tespit edilen ÜGIS malignitelerinin anatomik yerleşimi ve cinslere göre dağılımı Tablo l'de özetlenmiştir.

Yapılan histopatolojik incelemede, özofagus tümörlerinin \%84,1'i squamöz hücreli karsinom, \%15,9'u adenokarsinom; mide tümörlerinin $\% 87,9$ 'u adenokarsinom, $\% 3,8$ 'i malign epitelyal tümör, \%5,8'i lenfoma, \%2,5'i nöroendokrin tümör; duodenum tümörlerinin $\% 87,5^{\prime} \mathrm{i}$ adenokarsinom, \%12,5'i malign epitelyal tümör olarak tespit edildi. Özofagus kanserlerinin yaş dekadlarına göre sayısal dağılımı Şekil l'de, mide kanserlerinin sayısal dağılımı ise Şekil 2'de görülmektedir. Buna göre özofagus kanserlerinin en sık görüldüğü yaşlar 61-70, mide kanserlerinin en sık görüldüğü yaşlar 51-60 yaşları arasıdır. Özofagusta tümör görülen hastaların \%80'inde disfaji, \%20'sinde kilo kaybı; midede tümör görülen hastaların \%52'sinde epigastrik ağrı, \%20'sinde dispeptik şikayetler, \%14'ünde demir eksikliği anemisi, \%8'inde kilo kaybı, \%6'sında asit; duodenumda tümör görülen hastaların \%50'sinde karın ağrısı ve \%50'sinde sarılık semptomları vardl.

\section{TARTISMA}

Dünyada kanser tipleri arasında \%4,2 görülme oranıly sekizinci sırada olan özofagus kanserleri, ölüm sıklığı açısından

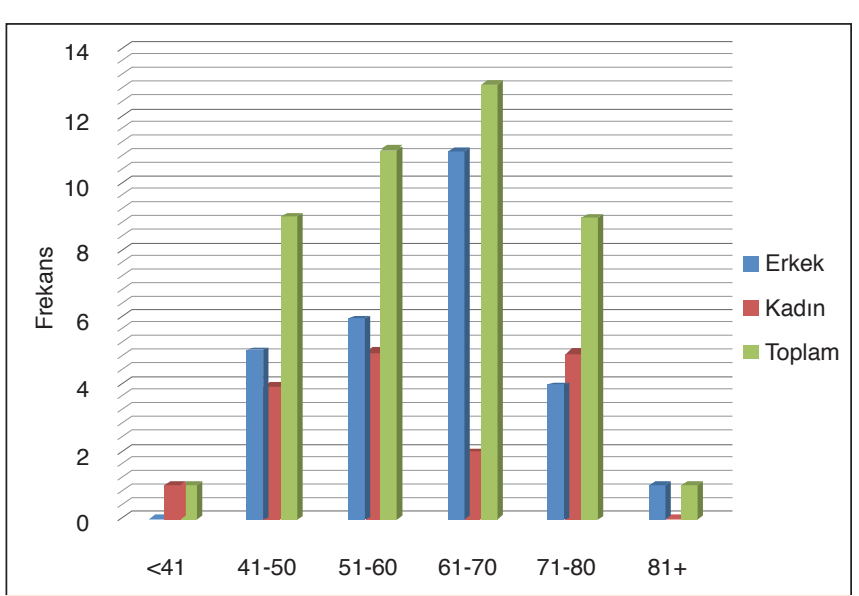

Şekil 1. Özofagus kanser olgularının yaş gruplarına göre sayısal dağılımı.

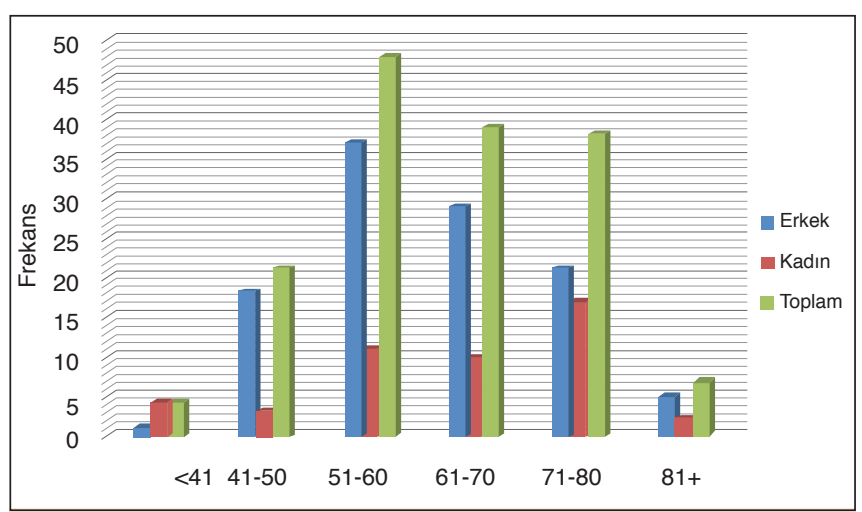

Şekil 2. Mide kanser olgularının yaş gruplarına göre sayısal dağılımı.

altıncı sırada yer almaktadır (1). Ülkemizin değişik bölgelerinde ÖGD yapılan hastalarda özofagus malignitesi görülme oranları araştırılmış ve Doğu Anadolu Bölgesi'nde \%4,3 (4), Eskişehir'de \%3 (5) olduğu bildirilmiştir. Çalışmamızda ise özofagus kanseri diğer bölgelere oranla oldukça düşük olarak, endoskopi uygulanan olguların sadece \%0.57'sinde saptanmıştır. Ülkemizde üst gastrointestinal sistem kanserleri, Doğu ve Güney Doğu Anadolu Bölgelerinde prevalansı yüksek, önemli morbidite ve mortalite nedenlerindendir. Ülkemizin doğusundan batısına geldikçe özofagus kanseri insidansında azalma olduğu görülmektedir. Özofagus kanserlerinin yaklaşık \%10'u özofagusun üst 1/3'lik kısmında, \%35'i orta 1/3'lik kısmında ve \%55'i alt 1/3'lik kısminda görülmektedir (6). Uzakdoğuda yapılan bir çalışmada özofagus malignitelerinin \%64'ü distal özofagusda saptanmıştır (7). Doğu Anadolu Bölgesi'nde ise bu oran \%88 olarak bulunmuştur (4). Çalışmamızda özofagus malignitelerinin \%74'ü distaldeydi. Son yıllarda distal özofagus malignitelerinin arttığı bildirilmiştir. Özofagus kanseri tüm dünyada erkeklerde kadınlara oranla daha fazla görülmektedir (6). Çalışmamızda dünya verilerine yakın bir şekilde özofagus maligniteleri erkeklerde kadınlardan 1,6 kat fazla saptandı. Bizim çalışmamızda özofagusta tümör görülen hastalarda görülen başlıca semptomlar disfaji 
ve kilo kaybıdır. Bu semptomlar özofagus kanseri açısından uyarıcı olmalıdır.

Dünyada akciğer ve meme kanserinden sonra 3. sırada görülen mide kanseri sıklı̆̆ı, coğrafi bölgelere göre değișiklik gösterir (2). En sık Japonya ve Çin'de görülürken Avrupa'da ylllı insidansı 100.000 'de 12-15'tir $(8,9)$. Sağllk Bakanllğı'nın kanser istatistiklerine göre; Türkiye'de en sık görülen beşinci $(9.92 / 100,000)$ kanser türüdür (10). Mide kanserinin görülme sıklı̆ı 30 yaşından sonra artar ve yedinci dekatta pik yapar. Erkek/ kadın oranı yaklaşık 2/l'dir (11). Çalışmamızda ÖGD işlemi ile tespit ettiğimiz malignitelerin \% 75, l'ini mide kanseri olarak saptadık. Kadın ve erkek görülme oranı ise literatüre benzer bulundu. Dökmeci ve ark.'nın Trakya bölgesinde yaptığı çalışmada mide kanserlerinin \%16'sı (12), Yüceyar ve ark.'nın Ege bölgesindeki çalışmasında mide kanserlerinin \%15'i kardiada saptanmıştır (13). Yaşa ve arkadaşlarının 2006 yılında Aydın'da yaptı̆̆ı bir çalışmada ise mide kanserlerinin kardiada görülme oranı \%20'dir (14). Rakic ve ark.'nın 19721976 ile 1986-1990 tarihleri arasında sirasıyla tespit ettikleri 386 ve 870 mide kanseri değerlendirmeye alındığında, önceki ylllarda midenin üst 1/3'lük kısmında tespit edilen mide kanserleri \%20,6 iken, sonraki yllarda bu oranın \%36,4'e yükseldiği görülmüştür (15). Çalışmamızda mide kanseri \%36,3 oranında kardiada tespit edildi. Bu oranın yaklaşık 10 yl önce kliniğimizde yapılan çalışmada \%20 bulunduğu dikkate alındığında son yıllarda dünyadaki diğer ülkelerde olduğu gibi ülkemizde de distal mide kanserlerinin insidansında bir azalma, proksimal mide kanserlerinde ise artış olduğu söylenebilir. Mide kanseri tespit ettiğimiz vakalarda en sık görülen semptomlar epigastrik ağrı ile dispeptik yakınmalardı. Hastalarda bu semptomlar tedaviye dirençliyse ya da ileri yaşlarda görülmüşse tanı için ÖGD düşünülmelidir. Japonya'da tarama programına alınması nedeniyle mide kanserinin erken tanı oranı artmış ve 5 yıllık sağ kalım oranı \% 86'ya ulaşmıștır (16). Ülkemizde de sik görülen ve yüksek mortaliteye sahip mide kanserlerinin erken tanısına yönelik ileriki zamanlarda ulusal tarama programına alınması düşünülebilir.

Ince barsak tümörlerinin \%33-45'ini oluşturan duodenum tümörleri, tüm gastrointestinal sistem tümörlerinin sadece $\% 0,3$ 'ünü oluşturur $(17,18)$. Çalışmamızda 8 adet duodenum kanserine rastladık. Bu hastalarda işlem öncesi temel semptomlar karın ağrısı ve sarılıktı. Duodenum tümörleri nadir görüldüğü için gözden kaçabilmekte ve ancak ileri evrelerde karşımıza çıkabilmektedirler. Bu nedenle sarılık ve obstrüksiyon ile birlikte karın ağrısı bulunan hastalarda duodenum kanserleri de akılda bulundurulmalıdır.

\section{KAYNAKLAR}

1. Parkin DM, Bray F, Ferlay J, et al. Global cancer statistics, 2002. CA Cancer J Clin 2005;55:74-108.

2. Parkin DM, Bray FI, Devesa SS. Cancer burden in the year 2000. The global picture. Eur J Cancer 2001;37(Suppl 8):S4-66

3. Yao KA, Talamonti MS, Langella RL, et al. Primary gastrointestinal sarcomas: analysis of prognostic factors and result of surgical management. Surgery 2000;128:604-12.

4. Tuncer I, Uygan I, Kösem M, et al. Van ve çevresinde görülen üst gastrointestinal sistem kanserlerinin demografik ve histopatolojik özellikleri. Van Tip Dergisi 2001;8:10-3.

5. Sarıçam T, Vardereli E, Harmancı A, et al. 1400 olguda üst gastrointestinal sistem endoskopisiyle saptanan maligniteler. Turk J Gastroenterol 1994:2:275-9.

6. Mayer JR. Gastrointestinal tract cancer. In: Fauci SA, Braunwald E, Hauser LS, Kasper LD, Longo DL, Jameson JL (eds). Harrison's Principles of Internal Medicine. 18th edition. USA, McGrawHill Company 2008;76476.

7. Liu SZ, Wang B, Zhang F, et al. Incidence, survival and prevalence of esophageal and gastric cancer in linzhou city from 2003 to 2009. Asian Pac J Cancer Prev 2013;14:6031-4.

8. Wayman J, Forman D, Griffin SM. Monitoring the changing pattern of esophagogastric cancer: data from a UK regional cancer registry. Cancer Causes Control 2001;12:943-9.

9. Terry MB, Gaudet MM, Gammon MD. The epidemiology of gastric cancer. Semin Radiat Oncol 2002;12:111-27.

10. TC Sağlık Bakanlığı Kanser Istatistikleri. Ekim 2012.

11. Metlin C. Epidemiologic studies in gastric adenocarcinoma. In Douglass HO (ed). Gastric cancer. New York: Churchill Livingstone 1988;1-25.

12. Dökmeci G, Ulusoy E, Özdemir S, et al. Mide kanserli 69 olgunun analizi. Turk J Gastroenterol 1996;7:335-9.

13. Yüceyar H, Ersöz G, Çoker A, et al. Evaluation of the clinical characteristic of the patients with gastric cancer: (10 years retrospective and prospective study). T Klin Gastroenterohepatoloji 1995;6:172-6.

14. Yaşa MH, Coşkun A, Yükselen AV, et al. Adnan Menderes Üniversitesi Tıp Fakültesi Hastanesi endoskopi ünitesinde yapılan üst gastrointestinal sistem endoskopisindeki malignite oranları. Endoskopi Kongre Özel Say1sı. 2006;16:209

15. Rakić S, Milićević MN, Kovacević P, Marković V. Increasing incidence of adenocarcinoma of the proximal stomach. Eur J Surg Oncol 1992;18:340-1.

16. Hosseini SN1, Mousavinasab SN, Moghimi MH, Fallah R. Delay in diagnosis and treatment of gastric cancer: from the beginning of symptoms to surgery--an Iranian study. Turk J Gastroenterol 2007;18:77-81.

17. Chung WC, Paik CN, Jung SH, et al. Prognostic factors associated with survival in patients with primary duodenal adenocarcinoma. Korean J Intern Med 2011;26:34-40.

18. Hu JX, Miao XY, Zhong DW, et al. Surgical treatment of primary duodenal adenocarcinoma. Hepatogastroenterology 2006;53:858-62. 